\title{
NIÑOS Y TELEVISIÓN: DE LOS ESTUDIOS SOBRE LOS EFECTOS A LOS DE RECEPCIÓN ACTIVA
}

\author{
Carmen Marta Lazo: Universidad Complutense de Madrid (España)
}

Nuria de Ángel García: Universidad Complutense de Madrid (España)

\section{Antecedentes de investigaciones relacionadas con consumo infantil de medios de comunicación}

Los primeros estudios realizados sobre televisión e infancia se centraron en los efectos, contando con antecedentes que analizaban la influencia del cine en los niños. En el campo del medio audiovisual, la investigación pionera se desarrolló en Gran Bretaña, donde en 1958, Himmelweit, Openheim y Vance publican un estudio empírico basado en entrevistas realizadas a niños de trece y catorce años, y profesores, estableciendo como criterio la comparación entre quienes tenían la posibilidad de ver la televisión y los que no.

Por la amplitud de la muestra seleccionada, seis mil niños y dos mil padres y profesores, y por el cambio en el planteamiento: qué hacen los niños con la televisión y no la televisión con los niños se caracterizó la investigación llevada a cabo por Schramm, Lyle y Parker en 1961, en la que se utilizaron como variables distintivas la edad y el sexo o la capacidad intelectual.

Los análisis sobre la repercusión del contenido televisivo y de las imágenes violentas en los niños han sido numerosos. En 1963, Bandura, Ross y Ross publicaron un estudio, de carácter conductista, sobre la causalidad entre ver violencia y manifestarla con actos agresivos. Es en 1971, cuando Linnée en un trabajo realizado en Suecia con niños de cinco a seis años introduce la variable contexto social como determinante en los efectos de los contenidos.

La teoría funcionalista sobre los efectos de la televisión en los destinatarios infantiles centra todas las investigaciones hasta que en la década de los setenta comienzan alternativas como la teoría del desarrollo cognitivo, que se basa en que "el niño es visto como un agente activo que a través de una maduración e interacción con el entorno, desarrolla con mayor eficiencia las habilidades cognitivas" (Vilches, 1993). Desde esta teoría los estudios que surgen tratan de investigar lo que aprenden los niños de manera activa de la televisión y no los efectos que ésta produce en ellos. Un ejemplo es el estudio que Salomon realiza en 1979 acerca de la influencia de "los códigos visuales en los procesos y habilidades mentales de los niños", según este investigador, "la extracción de información se realiza a través de una negociación activa de los códigos del mensaje. Con los años y la experiencia cambian los niveles de atención, comprensión y comportamiento de los niños. Pero al mismo tiempo, éstos se hacen capaces de entender mejor el lenguaje del medio, tanto las convenciones como los contenidos televisivos".

El cambio de los análisis desde una perspectiva cuantitativa hacia concreciones cualitativas en marcos y contextos específicos supondrán un cambio importante en la investigación del medio televisivo. Como se afirma en el Informe Marco sobre "La 
televisión educativa en España" (1996): "existe una urgente necesidad de dar respuestas acerca de la calidad de la recepción televisiva, de lo que significa el que unos determinados hogares tengan la televisión encendida frente a lo que realmente representa el atender con interés a unos u otros programas. La investigación cuantitativa rara vez se ha preguntado las relaciones de interacción entre los miembros del grupo familiar, o los usos y las mediciones con respecto al medio televisión. En un futuro, en el que las posibilidades de interacción con el medio se van a ir ampliando de forma geométrica, no tiene sentido remitirse exclusivamente a los estudios cuantitativos como forma hegemónica de seguimiento de las audiencias televisivas". Desde este planteamiento, surgen los trabajos de Fiske, Masterman, Llull, Kaplún, Martín Barbero o Guillermo Orozco. Estos tres últimos autores, en el contexto latinoamericano han venido realizando numerosos estudios fundamentados en la teoría de la recepción activa de la audiencia, utilizando técnicas grupales con el fin de que los diferentes componentes reflexionen de modo creativo sobre los mensajes televisivos. Desde estos parámetros hemos planteado nuestra investigación, con el fin de que los niños aprendan a interpretar críticamente y mediante métodos lúdicos los mensajes televisivos y sean conscientes de la importancia que ellos tienen en el proceso comunicativo, al ser seres que pueden decidir autónomamente desde el mismo momento de la elección de ver o no la televisión.

En cualquier proceso comunicativo es de suma relevancia atender al punto de llegada del mensaje, a los receptores y a la utilidad que ellos establecen del medio de comunicación, así como sus preferencias y alternativas que proponen. De este modo, el receptor deja de ser un mero espectador para convertirse y sentirse "expectante", es decir, actante, cómplice y participante, y no mero observador y víctima de la realidad adulterada que le ofrece la televisión.

Los niños actuales se diferencian de las anteriores generaciones en que ellos han nacido con la existencia de televisión y de nuevas tecnologías y, por lo tanto, la ven "como elemento 'natural' en su vida cotidiana y no se plantean el 'para qué' de la televisión, lo que aparece en otros sectores sociales (grupos de adultos). No perciben la existencia de un poder tras el medio, lo asumen como algo intrínseco al medio" (Gallego, 1995), por ello hay que formarles también para que aprendan a dilucidar los intereses que se esconden tras cada mensaje unidireccional y, de este modo, puedan argumentar sus críticas y responder con criterios solventes para debilitar "la potencia y la influencia de las ideologías dominantes, que los medios intentan presentar como incuestionables" (Masterman, 1985).

Si desde la infancia formamos ciudadanos críticos, la programación televisiva tendrá que ajustarse a sus gustos y cada vez será de mayor calidad, "el todo vale" o "dar más de lo mismo" se convertirá en decisiones más racionales por parte de los programadores, pues si en último término es la audiencia la que decide y ésta se prepara y alfabetiza en el lenguaje audiovisual, comenzará a discriminar lo que para ella no es válido y, desde un enfoque participativo y democrático, será la que decida. Las nuevas tecnologías validarán este modelo, ya que con la televisión por cable crecen considerablemente el número de canales y con la televisión digital, elegir "a la carta" y establecer cada uno la parrilla que le apetece ver hará que los esfuerzos por parte de los que hasta ahora sólo decidían aumenten en dar una oferta más amplia, más específica temáticamente y de mayor calidad. 
El paradigma que Laswell construyó en 1982, puede verse significativamente modificado: a quien responde qué, por qué canal, quién y con qué efectos. De este modo, la interactividad que propicia el desarrollo de las nuevas tecnologías en un proceso bidireccional es un hecho, llegamos así al concepto de EMEREC, como Jean Cloutier bautiza a la persona que es emisor y receptor al mismo tiempo, siendo un estadio posterior al período de la comunicación de masas, el de la comunicación individual, en el que "en lugar de receptores pasivos hablaremos de individuos que se van a informar al mismo tiempo que van a informar a otros" (Aparici y García Matilla, 1987), lo que ya están haciendo posible las redes digitales de información.

Roberto Aparici (1997) refiriéndose al enfoque centrado en el receptor afirma:

"Este modelo se preocupa por formar a las audiencias con el fin de que su actuación no se limite a ser sólo consumidores de mensajes sino a tener poder de decisión en los medios de comunicación. Este enfoque capacita a la sociedad civil con el fin de que tengan una presencia activa en los medios. Pretende que las decisiones que se toman sobre las audiencias no sean sólo las de tipo económico que refuerce el poder de los medios, sino que se establezcan canales de negociación para que la voz de la sociedad civil tenga una presencia real en el contenido y enfoque democrático de los medios".

No hay que olvidar tampoco que la búsqueda de lo alternativo puede resultar marginadora, tal y como recuerda Lolo Rico (1994):

"Al hablar de vida no puedo evitar referirme a aquella que se inicia, a la del niño, en definitiva, que viene desvalido a integrarse en un mundo en el que parece que está todo irremediablemente hecho. Insisto en el término que he utilizado: integrarse. Porque cooperar a que los que empiezan a vivir se adapten a una sociedad establecida, sin encender en ellos el deseo de cambiarla o mejorarla es, a mi juicio, hacerles un flaco servicio. Pero ejercer la crítica, educándoles en la disconformidad, tampoco les beneficia puesto que hoy es una grave rémora ser marginado (...) Capacitar la inteligencia y la sensibilidad para escoger entre lo bueno y lo malo, define María Moliner en su diccionario el concepto de educar, y elegir entre lo mejor y lo peor, entre lo aceptable y lo rechazable es siempre el fruto de una labor de reflexión y del ejercicio del espíritu crítico".

En este sentido, Neil Postman (1985) señala que no podemos olvidar que ningún medio es excesivamente peligroso si los usuarios conocen sus peligros.

Cuando un niño se siente dueño de los contenidos (los significados) y maneja las formas (los significantes) a su gusto obtendrá de ello un placer que ningún juego le puede dar (Mantovani, 1980).

El desarrollo de la creatividad, un objetivo en el currículo de las primeras etapas de la enseñanza supone un factor importante de cara a la creación de los propios productos audiovisuales por parte de los niños. Algunos soportes informáticos, como el CD Rom, ya permiten a partir del hipermedia "que el niño juegue y desarrolle su historia, elija personajes, escenarios y efectos según su voluntad. Incluso, por medio 
del reconocimiento de voz, el niño también puede doblar a sus personajes. La tecnología ya lo permite, pero los usuarios aún no demandan estos programas inteligentes" (Moreno, 1996).

Lo cierto es que hay que promover el paso de un receptor ingenuo ante los mensajes a un perceptor con capacidad de discernimiento, como afirma Mario Kaplún, autor que diferencia entre el receptor, quien "sólo recibe los mensajes, actúa como espectador de la realidad, no tiene opinión formada y se admira ingenuamente ante la técnica de los medios" y el perceptor, quien "sabe interpretar los mensajes, participa activamente en la realidad, tiene discernimiento y personalidad, tiene capacidad de elección y se esfuerza por comprender los lenguajes mediales".

\section{La programación televisiva en el contexto actual}

La programación televisiva destinada al público infantil no responde, en la actualidad, a los criterios mínimos de calidad que la legislación española y la Directiva Europea establecen desde 1989 al respecto y que a menudo son olvidados en pro de exigencias económicas y comerciales. En este sentido, se pronuncian numerosos autores, para Jorge Rioboo (1990): “...la mayor parte de los buenos programas para niños tienen el riesgo de ser suprimidos en provecho de programaspaquete (lote) de una calidad y de un gusto dudoso, a veces amorales y a menudo violentos, comprados a bajo precio en los mercados".

Por su parte, Lolo Rico establece dos funciones que deberían estar presentes en cualquier programa para niños:

"-Centrar al niño en una situación que explique de manera seria, clara y sincera la realidad que le circunda o que, al menos, le lleve a preguntarse por la naturaleza de esa realidad. O lo que es lo mismo: ideologizar - en el buen sentido de la palabra - ante el niño todas las situaciones a fin de que se acostumbre a ver en las cosas problemas y no falsas soluciones.

- Hacerlo siempre con las más altas exigencias estéticas y artísticas, tratando de asombrar al niño (en su sentido griego) con talento creativo en lugar de ofuscarlo con luces y confeti."

Para esta autora, si los programas infantiles cumplieran estas condiciones no serían sólo de interés infantil sino que llegarían a interesar al público adulto:

"Siempre he creído que lo que aburre al adulto, aburre también al niño. Lo que sucede es que el niño, sometido a un poder doméstico que le abandona ante el televisor antes de haber tenido tiempo de hacer acopio de otros recursos y menos capaz de discernir claramente la línea entre realidad y ficción, se resigna a dejarse encandilar por cualquier cosa. Sin embargo, no todo le es indiferente. La prueba es que rechaza, acepta y selecciona a través del zapping...".

A pesar de que no existan unos programas especialmente concebidos como televisión educativa, es innegable que la influencia de la televisión modifica de manera considerable la forma de educar. El educador debe pensar en la existencia de los medios y el programador de los medios no debe de olvidar las exigencias de 
la educación. La televisión como medio de comunicación social, como hemos indicado anteriormente, es uno de los agentes más potentes de socialización del niño al que transmite modelos de conducta, normas y moral social. También le permite conocer modos de vida, tramas de historia, tipos sociales y aspectos de la naturaleza que no están al alcance de sus experiencias inmediatas. Puede, asimismo, ser utilizada con éxito al servicio de los tiempos de ocio del niño, como estímulo a su imaginación, a las actividades lúdicas y a un esparcimiento enriquecedor. Por lo que es necesaria una programación adecuada que sirva de estímulo a la observación, a la asociación y al desarrollo del lenguaje y de las capacidades expresivas del niño.

Según Agustín García Matilla (1997) es a las televisiones públicas a las que corresponde unir esfuerzos para producir buenos programas que consigan captar el interés de la audiencia infantil desde formatos entretenidos que no renuncien a la formación de los telespectadores. "Las instituciones deberán aglutinar esfuerzos y hallar los recursos necesarios para que este objetivo se cumpla". En este sentido, en nuestro país ha habido varios intentos de estructurar la enseñanza de y con nuevas tecnologías, como han sido los proyectos Atenea y Mercurio en el campo de la educación.

No se puede tampoco olvidar que la sociedad tiene que ser consciente de esta realidad y participar activamente, ser críticos, seleccionar y exigir calidad en la programación de los medios de comunicación, por lo que hay que buscar alternativas al momento actual.

En la clasificación que realiza Moragas (1982) referente a los niveles comunicacionales establece los siguientes: Microcomunicación, nivel de comunicación grupal; Mesocomunicación, nivel local y regional; Macrocomunicacional, corresponde al ámbito nacional; y Megacomunicación, lo internacional. En opinión de este autor, sólo desde los niveles Micro y Meso es viable lo alternativo.

"Una alternativa viable debe partir de la realidad perceptiva de los destinatarios para evitar la disonancia cognitiva. La alternativa estará en la selección y tratamiento del contenido para que potencie los cambios deseados. Lo cual significa cambiar las prácticas de producción de significados recreando los espacios existentes en todos los niveles de la producción y en el marco de acciones no contestatarias, cuando estamos inmersos en un sistema democrático (...). Sólo promoviendo acciones alternativas capaces de penetrar en el tejido social con la misma efectividad que los medios de difusión actuales, y que estimule la participación y la organización popular, lograremos que la democracia formal se convierta en democracia real" (Tomás Eduardo Landivar: "Hacia una comunicación educativa alternativa", en Medios Audiovisuales, núm. 171).

\section{Trabajo de campo realizado con niños}

Hemos realizado un análisis a un total de 48 niños, estableciendo dos grupos de contraste, uno de control y otro experimental, cada uno de 24 niños. A su vez, se establecieron las siguientes variables divisorias: 
- La edad, formando cuatro grupos, cada uno de doce componentes, de 4, 5, 6 y 7 años.

- La clase socio-económica y cultural, dividiendo a los niños en tres grupos de

16 miembros de clase media-alta, media-media y media-baja.

- El sexo, para establecer si aparecen y a qué edad criterios sexistas en la visión de los diferentes mensajes y personajes televisivos.

El análisis se ha llevado a cabo en varios municipios madrileños de la zona sur de Madrid, del 18 de abril al 12 de junio de 1997.

Los objetivos que nos planteamos mediante este estudio, de carácter no generalizable, pero que nos sirve para analizar tendencias son:

- Hacer un diagnóstico de los hábitos, formas y finalidad del consumo televisivo para niños/as entre 4 y 7 años.

- Contextualizar los hábitos televisivos en función de las variables:

- Edad

- Sexo

- Clase social

En función de los objetivos que nos planteamos, tratamos de encauzar el estudio de modo comparativo realizando un reparto divisorio entre un grupo global de control y otro experimental. De este modo, se dividieron las sesiones en dos fases:

- Una primera de carácter cuantitativo, para establecer un primer diagnóstico de la situación global de los sujetos de estudio y de las variables que los influyen, la situación familiar y escolar. En esta fase inicial, se repartieron cuestionarios a niños, padres y profesores, sin establecer ningún criterio para no mediatizar sus respuestas, de manera descontextualizada (simplemente, se entregaron los cuestionarios sin dar pautas de la investigación a la que iban orientados, para que sus respuestas fueran lo más objetivas posibles). Esta fase también nos sirvió para recoger datos y para contrastar, al final de la investigación, los resultados primeros de los niños del grupo experimental con los últimos, una vez realizadas las diferentes sesiones de trabajo de alfabetización del medio audiovisual, para fijar su aprovechamiento y cambio en la concepción.

- Una segunda de carácter cualitativo, por medio de técnicas de observación, discusión dirigida y entrevistas con los niños del grupo experimental.

Por lo que respecta a la organización de las sesiones, partimos de la consideración de que el niño no posee mucha capacidad de resistencia a la fatiga, por lo que la duración media de cada sesión de trabajo se situaba en torno a la media hora de manera flexible, para que fueran los propios niños quienes expusieran la posibilidad de acabar la sesión.

Las sesiones se desarrollaron cronológicamente de la siguiente manera: 

control).

1.- Rellenar el cuestionario con los niños (grupo experimental y grupo de

Dibujos: - Del niño y su familia viendo la televisión

- De una televisión

- De un programa de televisión

- De un personaje de televisión

2.- Grupo experimental. Visionado de las láminas, con los siguientes criterios:

- Que fueran una actividad motivadora.

- Que tuvieran una dificultad graduada.

- Que fueran fácilmente evaluables.

- Con una explicación breve y sencilla para que el niño lograra entender el desarrollo del ejercicio.

3.- Explicación de las láminas:

- Diferencia persona/personaje

- Clasificación géneros

- Tipología formatos especiales).

4.- Audición sonidos de televisión (palabra, silencios, música, efectos

- Identificación programa/informativo

- Presentador

- Cadena

5.- Discusión dirigida y explicación.

Visionado imágenes televisión: Dibujos Animados.

6.- Discusión dirigida y explicación.

Visionado imágenes televisión: Series juveniles y series para adultos.

7.- Discusión dirigida y explicación. películas.

Visionado imágenes televisión: Programas nocturnos: reality shows y

8.- Discusión dirigida y explicación.

Fundamentos tecnológicos televisión.

9.- Segundo cuestionario.

Elegimos como técnica en las sesiones de visionado y audición la discusión dirigida con carácter lúdico porque fomenta "el autocontrol, la participación grupal, la responsabilidad ante la propia conducta y el respeto a las reglas, a la vez que constituye un medio de aprendizaje de comportamiento y pautas grupales de primera magnitud" (Enciclopedia de la Educación Infantil, 1993). Sólo a través de dispositivos conversacionales abiertos se pueden alcanzar las vivencias de los sujetos y, a partir de éstas, sus estrategias. Dispositivos como la entrevista en profundidad o la reunión de grupo son capaces de producir discursos de una manera 
más o menos espontánea, para ser después analizados desde una perspectiva pragmático-semántica (Gallego, 1995).

La grabación de las sesiones en vídeo fue un recurso para una posterior interpretación de sus reacciones, ya que en la expresión de su pensamiento se refleja su personalidad y el lenguaje gestual nos sirvió para observar su manera de desenvolverse ante los demás.

Las taxonomías de objetivos de aprendizaje se basan en una clasificación jerarquizada desde los más sencillos a los más complejos a la hora de establecer los contenidos.

Estas son algunas de las taxonomías conocidas según el tipo de conducta a la que se refiera el objetivo:

$\begin{array}{lll}\text { Taxonomía de Bloom } & ---- & \text { Cognoscitivo (Contenidos conceptuales) } \\ \text { Taxonomía de Dave } & ---- & \text { Psicomotor (Contenidos Procedimentales) } \\ \text { Taxonomía de Kratwhol --- } & \text { Afectivo(Contenidos Actitudinales) }\end{array}$

CONTENIDOS * CONCEPTUALES:

En la taxonomía de ámbito cognoscitivo:

aprende.

${ }^{*}$ Se ponen en primer plano los procesos intelectuales del sujeto que

*Son las taxonomías más trabajadas.

*Hay que destacar entre dichas taxonomías la de Bloom, quien define 6 niveles de aprendizaje cognoscitivo: Conocimiento, Comprensión, Aplicación, Análisis, Síntesis y Evaluación (Conclusión).

Hemos concretado los contenidos conceptuales en los siguientes apartados:

- Los medios de comunicación: Prensa, Radio, Televisión, Vídeo, Cine, Libros, Ordenador, etc.

- La Televisión.

de la señal.

- El soporte. Fundamentos Tecnológicos de la TV: transmisión

- Formatos.

- Géneros.

- Contenidos.

- Personaje vs. Persona.

- Ficción/realidad.

- Utilidad del Medio Televisivo.

\section{CONTENIDOS * PROCEDIMENTALES:}

La taxonomía de Dave categoriza el aprendizaje psicomotor en 5 niveles: Imitación, Manipulación, Precisión, Articulación y Naturalización.

Hemos estructurado los contenidos procedimentales en base al siguiente esquema:

- Reconocimiento de programas y personajes de TV.

- Identificación y rechazo de los personajes. 
- Descripción y valoración de los contenidos televisivos en función de las preferencias.

- Posibilidad de seleccionar autónomamente los programas de TV.

\section{CONTENIDOS * ACTITUDINALES:}

La taxonomía de Kratwhol distingue 5 categorías de aprendizaje en el ámbito afectivo: Recepción, Respuesta, Valoración, Organización y Caracterización.

Los contenidos actitudinales objeto de nuestra enseñanza-aprendizaje han sido:

- Despertar la curiosidad sobre cómo se hace un programa de TV.

- Defensa de los derechos y opiniones con actitud de respeto hacia los otros.

Nos hemos basado en algunas consideraciones que CENECA (Centro de Indagación y Expresión Cultural y Artística) propone en su programa de educación para la recepción que desarrolla en diferentes países de América Latina. La metodología que hemos planteado atiende a los siguientes criterios:

* Segmentada. El trabajo se ha concretado en un espectro de edad de 4a 7 años y se ha estructurado desde una perspectiva paidocéntrica. Además de esta variable también hemos considerado, a la hora de establecer los diferentes grupos, el factor sexo y la clase social.

* Cualitativa, basándonos en análisis de contenido a través de discusiones dirigidas y en la utilización de técnicas proyectivas y entrevistas en profundidad.

* Grupal (división en dos grupos: experimental y control. Estratificado en función de las siguientes variables: edad, sexo y clase social).

En cada grupo se utilizaron técnicas de participación activa, estableciéndose distintos tipos de relaciones diádicas (uno-uno) y polidiádicas (uno varios), con el fin de generalizar el aprendizaje y animar a la toma de palabra para exponer sus propios criterios y argumentarlos.

* Contextualizada. Las unidades de población muestral se enmarcaron dentro del Sur de la Comunidad de Madrid, en las localidades de Leganés y Fuenlabrada.

* Motivadora. (Aprendizaje lúdico, utilizándose la actividad-juego como proceso fundamental del aprendizaje, según la concepción de Mario Kaplún).

También nos hemos fundamentado en algunos de los criterios que, según Cherry (1988), garantizan la motivación en los niños:

"- Durante el transcurso de la actividad, demostrar interés y reforzar el producto obtenido.

- No esperar la finalización del trabajo para ayudar al niño a complacerse, ya que tanto valor tiene el goce del producto como el del proceso creativo. 
- De producirse por parte del niño la petición de ayuda durante su trabajo, ofrecer la precisa sin exceder del punto óptimo, que es el momento en que el niño recupera el control y la iniciativa.

- Evitar valoraciones estéticas adultas sobre las obras plásticas infantiles, que cuentan con criterios de valor absolutamente distintos".

Para fundamentarnos en parámetros objetivos, siguiendo una línea de investigación científica, nos hemos basado en datos cuantitativos. No obstante, hemos mantenido reuniones en grupos empleando la técnica de discusión dirigida para "hacer emerger ideas y conceptos vivos" (Ricardo Berea, 1992) y así conseguir interpretar los datos.

Sujetos de estudio:

- Grupo de Control (análisis cuantitativo): * Cuestionario

(Ha sido la técnica empleada para profundizar en los aspectos más teóricos y globales del estudio, con el fin de establecer las relaciones y diferencias entre los sujetos de estudio).

- Grupo Experimental (análisis cualitativo): * Cuestionario

* Láminas

* Sonidos TV

* Imágenes TV

(Por medio de la subjetividad de las opiniones expuestas, se ha tratado de llegar a descubrir la objetividad de las estructuras de opinión que en tal contexto se han formado).

\section{Análisis de resultados}

\subsection{Cuestionarios}

En cuanto a las respuestas realizadas por los niños en los cuestionarios, observamos los siguientes resultados:

- Actividades de reposición:

Hasta los 6 años no comienzan a distinguir las unidades temporales, simplemente responden "mucho, poco, bastante", esto es debido a que el concepto de tiempo es una noción abstracta y difícil, que excede de la capacidad de los niños de Educación Infantil, como afirmaba Piaget (1969): "El tiempo no se ve ni se percibe jamás como tal, puesto que contrariamente al espacio o a la velocidad, aquel no entra en el dominio de los sentidos".

Casi todos ayudan a realizar las tareas domésticas del hogar (poner la mesa, limpiar el polvo,...), la respuesta más curiosa es que un niño de 4 años considera ayudar el acto "de encender la televisión".

- Actividades frecuentes: 
Los más pequeños interpretan "estudiar y leer" como dibujar y pintar y los niños de Primer Ciclo de Enseñanza Primaria ya comienzan a repasar sus lecciones aunque, en la mayoría de los casos no lo hacen todos los días.

La mayoría juegan solos, sobre todo los que no tienen hermanos de su edad. Muchos responden que "juegan con videojuegos". Suelen jugar con otros niños en el parque o en el colegio y los que tienen hermanos en su casa, pero son pocos los que indican que juegan con sus padres $u$ otros adultos y menos cuando éstos trabajan, es entonces cuando la televisión se convierte en "niñera electrónica".

- Actividades uso medios de comunicación:

La televisión es el medio que más utilizan en todas las edades y grupos sociales, la respuesta más común es verla todos los días durante "mucho" tiempo. La radio la escuchan "a veces" y "porque la ponen sus padres", se percibe que la programación radiofónica no les resulta atractiva. En cuanto a la prensa, es el medio menos utilizado, bien porque no saben leer los más pequeños o porque prefieren leer cuentos. Los niños de 6 y 7 años muestran mayor curiosidad, les gusta "mirarla de vez en cuando". Una excepción es un niño de 7 años que dice leer "todos los días 3 horas diferentes periódicos, porque soy ciudadano del mundo y me gusta estar informado". Al cine suelen ir "algunas veces al mes", sobre todo los más pequeños lo confunden con el vídeo porque afirman hacer uso de él "en casa". Escuchan música "a veces" y muchos disponen de su propio cassette. Los libros en las edades más tempranas no son utilizados autónomamente, sino que se los lee un adulto, y los más mayores no tienen demasiado hábito de lectura, algunos los asocian con los textos escolares. En lo referente al vídeo, la mayoría afirman ver varias películas a la semana, las que prefieren son las de Disney; algunos también indican que les sirve para aprender inglés.

- Cómo y cuando ven la televisión:

En general, ven más la televisión los fines de semana y prefieren los horarios de tarde, sobremesa y tarde en ese orden. Los niños más pequeños responden casi en su totalidad verla con su familia y se observa que el visionado compartido va disminuyendo conforme van creciendo, bastantes señalan que tienen televisión en su habitación. Además de verla en casa, también afirman hacerlo en el colegio, lo que nos permite observar que la confunden con las grabaciones en el vídeo, al hacerse uso de la pantalla.

\section{- Géneros preferidos:}

Entre sus preferencias destacan los dibujos animados, en todas las edades, seguidos de las películas infantiles de "Disney" y de las series españolas, antes de pasar al apartado de programas concretos fueron muchos los que nos indicaron que les gusta "Médico de Familia" sólo mencionando la palabra "series". En un segundo plano, quedan los programas infantiles y los documentales "de naturaleza", que si bien no eran elegidos en primer lugar sí que entraban en sus preferencias. Se observa alguna mención a los informativos aunque suponen excepciones y en ningún caso seleccionan las películas de mayores. 


\section{- Programas preferidos:}

Las series de dibujos animados que prefieren son "Los Pitufos", "Inspector Gadget", "La Banda de Mozart" y "Los Picapiedra", por este orden. Las series también se incluyen entre los programas que más les gustan, las más mencionadas son "Médico de Familia" y "Querido Maestro". Es curioso que el fútbol también está entre las preferencias de los niños de sexo masculino, pues las niñas lo incluyen en los programas que menos les gustan.

Hay que destacar que hasta los 7 años no comienzan a identificar los programas con la cadena a la que pertenecen.

- Programas que menos les gustan:

Así como los programas preferidos son nombrados con su título concreto, en los que menos les gustan existen escasas referencias a contenidos, sino más bien a algunos elementos formales: "los de sangre", "los que se pegan",...

Ocupan un lugar destacado los informativos, seguidos de las películas de miedo y de violencia y en las que "hacen guarrerías", como definen las imágenes en las que aparecen escenas de sexo. A los 7 años se observa cómo algunos niños sienten como van evolucionando, al responder que no les gustan "las películas para bebés". Entre los niños más pequeños, los "Power Rangers" es una serie que rechazan "porque se pegan", siendo menos nombrada por los más mayores, también se aprecia que son más las niñas que la nombran, pues algunos niños, los menos, la incluyen en sus preferencias. Un programa que es muy nombrado por los niños de estas edades y calificado como "muy malo" es "El Semáforo" "porque hacen tonterías" y no les suele gustar.

- Personajes que más les gustan:

Los personajes Disney que están de moda son los que más prefieren: "Los de los 101 Dálmatas", "del Jorobado de Nôtre Dame", "del Rey León", incluso se aprecia el bajo índice de caducidad de estas series y personajes, otros que nombran son: "Minnie", "Mickey", "Pluto", "Donald", "Bugs Bunny"... También destacan entre sus preferencias: los personajes de "Los Pitufos", muchas niñas simpatizan con "La Pitufina". Otros identifican el personaje con el programa "el de Médico de Familia", refiéndose a "Nacho (Emilio Aragón); "el de Querido Maestro" (Mario, papel que interpreta Imanol Arias) y también hay niños que elevan a los futbolistas hasta el grado de convertirse en sus ídolos de la pantalla (Kiko, del Atlético de Madrid).

- Personajes que menos les gustan:

Aquí surgen los estereotipos de "los buenos vs. los malos", así se nombra a "Los malos de los Pitufos o Gargamel y su gato", "La mala de Nôtre Dame",... 
Muchos confunden los personajes con presentadores de televisión, aspecto que también se contempla en el apartado anterior, y mencionan a los "presentadores de los informativos" entre sus menos preferidos.

Un apunte curioso es la respuesta de uno de los niños: "los que ve mi madre...".

\subsection{Interpretación de los dibujos}

En cuanto a la interpretación de los dibujos realizados por los niños, atendiendo a las observaciones que hacen los autores Eines y Mantovani (1980), a través de los dibujos, podemos concretar el estadio evolutivo del niño, así como su capacidad de representación simbólica de la realidad que le circunda. Para dichos autores: "El dibujo es la expresión gráfica de las funciones de representación. En un primer estadio, tenemos el garabato que no representa nada, sólo imita la escritura o dibujo de los adultos. Si, posteriormente, el niño descubre cierta semejanza entre sus garabatos y un objeto o imagen, le da a aquellos un nombre. En un segundo estadio, el niño representará simbólicamente a través de su dibujo la realidad. Esto lo hará dibujando la representación que él se ha hecho del objeto y más tarde dibujando el objeto no como lo ve sino lo que sabe de él". Esta teoría se aprecia en nuestro estudio a través de los dibujos que realizaron los niños de 4 a 7 años.

Las distintas etapas en la evolución del dibujo infantil se observan con nitidez, así nos encontramos con niños de cuatro y cinco años que representan un estadio de realismo simbólico alejándose del garabateado. En algunos casos, los niños comienzan a dibujar con un trazo definido y cerrado algunos detalles, coloreando los contornos con mayor precisión, y empezando a distinguir las gamas cromáticas.

Los niños de 6 y 7 años empiezan a consolidar sus trazos y detalles y, las distintas perspectivas y planos comienzan a estar presentes en sus dibujos.

Este ejercicio consistió en que los niños realizaran cuatro dibujos diferentes:

1. A él y a su familia viendo la televisión.

2. Una televisión.

3. Un programa de televisión.

4. Un personaje de televisión.

Del primer dibujo es curioso constatar como los niños reflejan la realidad familiar, por ejemplo, los hijos de padres separados muestran esta situación dibujando a los miembros que conviven en el hogar, bien a la madre o bien al padre. En otras ocasiones, la televisión sirve para dividir a la familia en dos: la del padre y la de la madre.

Los sujetos de estudio que afirman ver más horas de televisión, la dibujan encendida con algún contenido, en contraposición algunos niños la dibujan apagada porque prefieren estar "jugando en la calle" o bien porque están realizando otras actividades extraescolares: kárate, inglés, informática, etc. Atendiendo a las edades, observamos como los niños más mayores son más precisos a la hora de dibujar los detalles: mando a distancia, antena, interruptores, etc.

En lo referente a los dibujos de programas y personajes televisivos, los más pequeños se decantan generalmente por los dibujos animados, mientras que los de siete años representan, en ocasiones, espacios y personajes pertenecientes a series juveniles y de adultos. 
La evolución en las perspectivas se aprecia, sobre todo, a partir de los 6 años, que representan con mayor precisión la ubicación espacial y las proporciones.

En cuanto a los contenidos, algunos niños dibujan los documentales de animales como los programas que les resultan más interesantes.

\subsection{Imágenes fijas: láminas}

Para este análisis elaboramos un total de once láminas, de las cuales las tres primeras corresponden a la programación infantil de dibujos animados, las dos siguientes hacen referencia a programas contenedores, a dibujos animados y a series infantiles destinadas a niños entre 6 y 12 años. Otras dos láminas pertenecen a series juveniles y de adultos, distinguiendo entre las de producción propia y las de producción extranjera. Las láminas restantes están dedicadas a la programación de adultos y distribuidas de la siguiente manera: en una de ellas aparecen los programas documentales, informativos y deportes; a continuación se incluye una lámina referente a programas concurso y humorísticos. Concluimos nuestra serie con dos láminas de presentadores/as y personajes famosos de la televisión.

La ubicación en la página y la presentación en color o en blanco y negro obedece a que hemos querido situar distintos puntos de impacto visual en las láminas, con el fin de condicionar la elección.

Con este ejercicio hemos pretendido valorar distintos aspectos que van desde el índice de caducidad de las series y programas, a la identificación o rechazo de los niños con determinados personajes o programas atendiendo a diversas razones: sexo, violencia, valores estéticos, morales y sociales.

Hemos intentado constatar la evolución de estas variables en función de la edad y sexo de los niños que han intervenido en este estudio. Por otra parte, averiguar los gustos en cuanto a diferentes géneros y formatos televisivos, así como los horarios en los que se emiten. En este sentido, sorprende el alto porcentaje de niños que afirman reconocer y ver habitualmente programación destinada a público adulto emitida en horario nocturno.

\section{- Datos referidos a niños de cuatro años:}

De todos los contenidos de las láminas expuestas, en los niños de esta edad, observamos un mayor reconocimiento de series y personajes pertenecientes a dibujos animados y a programas infantiles ("Pitufos" 100\%, "Barrio Sésamo" 83,3\%, "La Banda de Mozart" 75\%, "Club Megatrix" 64,4\% y Leticia Sabater 50\%).

Perduran los personajes y programas basados en el recuerdo, como por ejemplo, el personaje de "Espinete" perteneciente a "Barrio Sésamo", desaparecido de la pantalla hace algún tiempo y que, sin embargo, los niños siguen asociándolo al programa.

En lo referente a personajes y series juveniles y de adultos el reconocimiento se sitúa en torno al 33,2\%, destacando "Médico de Familia", "Querido Maestro", "Hércules" y "El Equipo A".

En concursos y programas humorísticos, el índice de reconocimiento por parte de los niños es muy alto: "El Semáforo" (100\%), "La Parodia Nacional" $(66,4 \%)$, "Los Morancos" (33,2\%). 
El reconocimiento del nombre de presentadores y personajes de magazines y reality shows es prácticamente nulo, aunque cabe destacar que al 16,6\% "les suena" Pepe Navarro.

Los niños se identifican positivamente con personajes que reproducen el esquema infantil y destaca su elección y preferencia hacia personajes poco violentos y buenos. Los héroes son siempre "guapos y buenos".

En este estadio, percibimos escasas connotaciones sexuales en la identificación con los personajes. Los principales temas argumentales para la elección o el rechazo se basan en los siguientes estereotipos: guapo/feo, bueno/malo o tiene/no tiene. Además, algunos determinan su criterio en función de que los personajes o los programas en que se inscriben sean "de niños/ de mayores".

Teniendo en cuenta los contenidos establecidos, los niños de esta edad aún no consiguen distinguir géneros y formatos, ni tampoco diferenciar la ficción de la realidad, asimismo existe una gran confusión entre persona y personaje.

\section{- Datos referidos a niños de cinco años:}

Existe un mayor reconocimiento de nombres concretos de personajes pertenecientes a dibujos animados y series infantiles, ("Los Pitufos" 100\%, "Super Mario" 100\%, "Los Picapiedra", "La Banda de Mozart" 75\%, "Lucky Luke" 50\%). Siguen perdurando personajes en el recuerdo como es el caso de "Espinete", a quien dicen reconocer en la imagen perteneciente a "Barrio Sésamo" En lo que a series infantiles y juveniles se refiere, el índice de reconocimiento aumenta ligeramente, así el 100\% de los niños reconocieron a "Spiderman", frente al 66,4\% de las niñas, ya que su interés por este personaje era menor. "Mortadelo y Filemón" gozaron de un $83,3 \%$ de reconocimiento tanto en niños como en niñas, argumentando que los conocían más por los cómics que por sus dibujos en televisión. En este porcentaje se sitúa también la figura del "Jorobado de Nôtre Dame”, comentando que no sólo lo conocían por la película cinematográfica, sino también por cuentos. "Los Simpson" se sitúan en un $66,4 \%$ en el índice de reconocimiento en dibujos o series destinadas a un público de mayor edad.

Entre las series españolas destinadas a jóvenes y adultos destacamos el reconocimiento de la serie "Médico de Familia" que fue reconocido en un 83,3\% de los casos, "Lina Morgan", "Querido Maestro", y la serie de "El Fary" se sitúan en un $66,4 \%$. A veces el reconocimiento se hacía completo, es decir, el título de la serie así como el nombre de sus protagonistas.

Los criterios de selección, aceptación o rechazo, siguen siendo: bueno/malo, guapo/feo, "porque ayuda a la gente", "porque tiene pistola", etc. En cuanto a identificación positiva, siguen perdurando los personajes basados en el esquema infantil pero en menor cuantía (25-50\%).

Significativo es que un $25 \%$ contesta que no se identifica "con nadie" o "con ninguno", comenzando a ser conscientes de su propia identidad. Apreciamos ya en este estrato de edad la identificación de niños con personajes masculinos y de niñas con personajes femeninos, criterio sexista teniendo en cuenta que para algunos es motivo de rechazo un personaje que sea del sexo contrario.

En lo que a programas informativos se refiere, la mayoría de los niños los identifican como "Las Noticias" o "El Telediario", el índice de reconocimiento se sitúa en el $66,4 \%$, superando al grupo de edad posterior. En cuanto a deportes, el fútbol sigue siendo el más identificado y el que más gusta. El 83,3\% lo reconoció, algunos hasta 
creen reconocer algún jugador en concreto como "Kiko", Alfonso", etc., futbolistas muy populares entre los chavales. El resto de deportes tiene un índice de reconocimiento bajo que oscila entre el $33,2 \%$ y el $16,6 \%$.

En lo concerniente a programas humorísticos y magazines, los concursos "¿Qué Apostamos?" o "El Semáforo", son reconocidos en un 33,2\% de los niños, en cuanto a presentadores de los mismos y personajes de la televisión, los más nombrados resultaron: "Ana", "Constantino", "Chiquito", "Los Morancos" y el más popular de todos "Karlos Arguiñano" a quien identifican con nombre y apellido.

Antes de las sesiones de trabajo y de las explicaciones sobre los medios, estos niños confunden lo que pertenece a la ficción y a la realidad (salvo en lo que a dibujos animados se refiere donde sí hacen alguna excepción) no aprecian distinción entre persona y personaje, así como las diferencias entre géneros y formatos tampoco son percibidas.

\section{- Datos referidos a niños de seis años:}

En esta edad, se incrementa considerablemente el grado de reconocimiento de series infantiles y de sus personajes. Un 100\% reconocen por su nombre a "Los Pitufos", "Mario Bross", "La Banda de Mozart", "Los Picapiedra", así como el programa contenedor "Barrio Sésamo" en el que el factor recuerdo sigue siendo importante, un 66,4\% también nombra al antiguo personaje de "Espinete". Además se observa que los niños distinguen en qué soporte ven los dibujos: "El Jorobado de Nôtre Dame" en vídeo o "Los 101 Dálmatas" en el cine.

Respecto a la programación para jóvenes y adultos también aumenta el reconocimiento, principalmente de las teleseries: "Médico de Familia" (100\%), "Xena" y "Hércules" (83,3\%), "Hostal Royal Manzanares/Lina Morgan" (66,4\%), "Querido Maestro" (50\%)...

Los informativos sólo son reconocidos, en las láminas, por la mitad de los niños de seis años (50\%) y en la mayoría de los casos los rechazan porque, según afirman "son aburridos". En cuanto a los deportes, destaca el fútbol $(83,3 \%)$, le sigue el tenis, el baloncesto y el ciclismo, con un $50 \%$. Hay que destacar que los documentales o "reportajes de naturaleza", como los califican, son mencionados en un $50 \%$ de los casos, en mayor medida que los niños de 7 años.

Los magazines y concursos también poseen un alto porcentaje de reconocimiento: "Los Morancos", "Menudas Estrellas", "Qué apostamos/Ana Obregón", "El Semáforo", un 66,4\% respectivamente. Por otra parte, es Arguiñano el presentador más popular entre los niños de esta edad (100\%).

Los presentadores de reality shows son poco conocidos, el índice se sitúa en torno al 16,6\%: Teresa Campos, Pepe Navarro, Ana. En algunos casos, oscila: Francis Lorenzo (por Efecto F), un 33,2\%, o Nieves Herrero, un $0 \%$.

El índice de reconocimiento suele ir parejo al de visión, así nuestra muestra de audiencia de 6 años prefiere los dibujos animados, destacan "Los Pitufos" y "Los Picapiedra" entre los más vistos (100\%); entre las series juveniles, "Hércules" $(100 \%)$ y de las de adultos, la excepción es "Médico de Familia" (100\%); el fútbol $(83,3 \%) ;$ los documentales $(50 \%) ;$ y entre los magazines y humorísticos: "De Domingo a Domingo" y "Los Morancos" (66,4\%). El programa gastronómico de Karlos Arguiñano coincide con el índice de reconocimiento, manteniendo un 100\% de televidentes. El porcentaje es nulo $(0 \%)$ en el caso del programa "El Semáforo" a través de la lámina, pues al hablar de dicho programa si lo reconocen, aunque 
afirman que no les gusta, lo mismo sucede con las presentadoras María Teresa Campos y Nieves Herrero.

En lo que respecta a la identificación, se observa que son más descriptivos y que comienzan a abandonar los estereotipos que prevalecían en las edades anteriores a la hora de "argumentar" sus preferencias. "Ser divertido", "graciosos", "amable" o "salvar/ayudar a la gente" son algunas de las pautas que ellos siguen al identificarse con personajes o presentadores. También los eligen por la profesión que interpretan: "porque es fontanero", "porque es un vaquero", "porque es profesor",...; o por sus pertenencias (sentido de la posesión): "porque tiene gorra", "por su traje", "porque me gusta su sombrero",... También asumen el componente estético como un fundamento en identificación: "está cachas", "es fuerte", "es guapa",...

Como motivo de rechazo, el componente sexista es mayor en las niñas que en los niños de esta edad, globalmente también aumenta la proporción con respecto a los niños de 5 años.

Es destacable que en esta edad, comienzan a asociar el programa y presentador o personaje a la cadena que pertenece o en la que se emite. Por otra parte, continúan apreciándose confusiones entre géneros y formatos, así como entre lo perteneciente a la realidad y a la ficción, aunque algunos ya comienzan a diferenciar entre persona y personaje.

- Datos referidos a niños de siete años:

Como hemos podido observar, el reconocimiento de los personajes de la programación infantil en general aumenta conforme la edad de los niños, así nos encontramos con que a los 7 años la totalidad (el 100\%) reconoce a "Los Pitufos", "Mario Bross", "La Banda de Mozart", "Los Picapiedra", "La Máscara", "Spiderman", "Mortadelo y Filemón", "Casper", "Bugs Bunny", "Los Power Rangers", "Los 101 Dálmatas" o "Barrio Sésamo". También crece el índice de los de series juveniles y de adultos: "Los Simpson", "Médico de Familia" (100\%), "Lina Morgan (Hostal Royal Manzanares)" (100\%), "El Fary (Menudo es mi padre)" (100\%), "Xena", "Hércules" $(83,3 \%)$, "Los Vigilantes de la Playa" (83,3\%), "Querido Maestro" $(66,4 \%)$, "El Equipo A" (50\%) y "Todos los hombres sois iguales" (50\%). Se aprecia que, en algunos casos (El Fary o Lina Morgan), nombran a los protagonistas en lugar de las series, toman así la parte por el todo.

Es significativo que los informativos son reconocidos por el $100 \%$ de los niños, mientras que el fútbol "sólo" por el $64,4 \%$, porcentaje menor que en las edades anteriores, hay que tener en cuenta también el rechazo que este deporte sufre por parte de las féminas de esta edad.

El índice de los magazines, los programas humorísticos y los concursos aumenta, así el 100\% reconocen a Chiquito de la Calzada y "El Semáforo", y el 83,3\% "Los Morancos". Lo mismo sucede con los reality shows y sus presentadores, aunque siguen siendo los menos reconocidos: Teresa Campos (50\%), Nieves Herrero $(33,2 \%)$ y Pepe Navarro (16,6\%). El líder vuelve a ser el conductor de un programa gastronómico, Karlos Arguiñano, con un 100\%.

Se observa una notable diferencia entre lo que reconocen y lo que ven, saben discriminar entre lo que les gusta y lo que no. Mientras que el $100 \%$ reconocía a "Spiderman", "La Banda de Mozart" o "Barrio Sésamo", sólo un 33,2\% ve estas series o programas infantiles. También es significativo que algunas películas de Disney como "Los 101 Dálmatas" o "El Jorobado de Nôtre Dame", pese a no 
haberlas visto en vídeo o en el cine, las conocen por otros soportes de publicidad añadidos, como son vallas, cromos,...

Por lo que respecta a las series juveniles y de adultos, "Médico de Familia" sigue siendo la más vista, parece que ninguno de los niños "se la pierde", pues "cuando se hace tarde, me la graba mi madre", responde uno de ellos. Le siguen: "El Fary (Menudo es mi padre)", "Lina Morgan (Hostal Royal Manzanares), "Todos los hombres sois iguales", con un 66,4\%. Porcentajes más elevados que los de las series juveniles: "Hércules" y "El Equipo A" (50\% cada una), y "Xena" (33,2\%).

Los informativos y documentales, a pesar de ser reconocidos en un alto porcentaje, no son los más seguidos por los niños de esta edad, un 50\% y un 33,2\% respectivamente.

De los programas concurso y magazines, eligen "El Semáforo" (100\%), pese a que después suelen rechazar a algunos de sus personajes. También afirman ver: "Los Morancos", "Menudas Estrellas", "La Ruleta de la Fortuna", en un 50\% de los casos. Programas como el de María Teresa Campos ó "Caiga quien caiga" son los menos vistos, un $0 \%$ y un $16,6 \%$, respectivamente.

Estos niños justifican su decisión a la hora de identificarse o rechazar programas, al igual que los anteriores, de manera más argumentada que los de las edades inferiores, en función de parámetros como el sentido estético: "porque es guapa y además me gusta su vestido rosa", "por su traje y por su pelo",... La identificación con personas de su sexo y el rechazo con las del sexo contrario se hace más evidente, y siguen siendo las niñas las que más prefieren o rechazan atendiendo a este factor: "porque es la única chica" (identificación), "porque no es una chica" (rechazo).

También es destacable la relación que establecen entre no ver los programas y rechazarlos: "no me gusta ninguno, no los veo", lo que hace patente su sentido crítico.

Al igual que los niños del resto de edades, antes de trabajar con ellos los diferentes contenidos conceptuales que se indican, en esta primera fase de seguimiento experimental, continuaban confundiendo lo que era un género y un formato, $y$ diversos matices entre la realidad y la ficción, aunque como los niños de 6 años, en este primer acercamiento, ya comenzaban tenuemente a distinguir las diferencias entre persona y personaje.

Como hemos podido apreciar, los niños en esta fase de visión de imágenes fijas no toman la violencia o el sexo como motivo de rechazo, factores que surgirán en otras etapas posteriores de nuestro estudio, como es la visión de las imágenes de vídeo o cuando se les pregunta abiertamente lo que menos les gusta de la televisión.

\subsection{Identificación sintonía-programa}

Los niños poseen mayor índice de recuerdo de las imágenes que de los sonidos y recuerdan más la información audiovisual que cuando sólo se presenta auditivamente. En este sentido, Lorenzo Vilches (1993) -recordando a Bruner- afirma que los niños "dependen primariamente de la representación icónica y por ello encuentran más dificultad en procesar la información verbal, que es más simbólica que la visual. Cuando posteriormente ellos desarrollan la capacidad de pensamiento simbólico perfeccionan el procesamiento verbal sin perder la capacidad visual". Así lo hemos corroborado en nuestro estudio sobre la identificación de diferentes 
programas de televisión, correspondientes a diferentes géneros y formatos televisivos, a través del audio de sus sintonías.

El objeto de este ejercicio fue explicar a los sujetos de estudio la importancia del sonido que, junto con la imagen conforma el producto audiovisual. Antes de las explicaciones, algunos niños creían que lo que iban a escuchar, grabaciones de sintonías de cadenas y programas de televisión, era "la radio", asociación obvia al utilizar como soporte un magnetoscopio reproductor.

En la alternancia entre sintonías de espacios culturales, deportivos, divulgativos y de variados formatos como reality shows, concursos, informativos, series infantiles y de adultos, etc. emitidos en distintas franjas horarias conseguimos que los niños, a través de una discusión dirigida, hicieran patentes sus preferencias. Además, observamos las diferencias en la identificación por grupos de edad, sexo y hábitos de consumo televisivo.

Comenzamos la escucha con la sintonía de la cadena Antena 3, sólo los niños más mayores lograron identificarla, lo curioso es que la reconocieron no como sonido perteneciente a... sino como "una televisión" en sí misma. La respuesta que más sorprendió fue el término con el que la definió una niña de siete años de clase media-media: "es el altavoz de la 3, de Antena 3".

El segundo audio seleccionado fue el del programa "Lo que necesitas es amor", la mayoría de los niños al escuchar la primera estrofa musical lo reconocieron y cantaron. Casi todos afirmaron haberlo visto alguna vez pero no por ser elegido por ellos sino porque se ve en su casa: "es lo que ve mi madre el domingo por la noche, me gusta", indicaba una niña de clase media-baja de 7 años, quien establecía una analogía con otro programa: "es como lo de Corazón, Corazón, pero diferente, por eso se llama Lo que necesitas es amor". La poca atención que prestan a este programa se evidencia en la confusión que hacen de su contenido con el de otros espacios del mismo formato: "Conocen a gente que, a veces no se ven o no se han visto desde hace cuarenta años...", también confunden a su presentador con otros, pese a que lo describen: "es un poquito calvo, también ha hecho La Parodia Nacional".

La siguiente sintonía pertenecía al programa deportivo "EI Domingol", la totalidad de los niños lo reconocieron inmediatamente, incluso lo asociaron con la cadena en la que se emite, La 2 de TVE. Al igual que en la práctica que realizamos con láminas, se aprecia que los niños son seguidores del fútbol y las niñas lo suelen rechazar: "a mí no me gusta el fútbol porque es muy feo", opinión a la que espontáneamente responde un niño "IAnda ya!". Además admiten que son sus padres quienes ven el programa mientras en otro receptor del hogar sus madres eligen otros, nos sirve esta respuesta de una niña de cuatro años de clase media-media como ejemplo: "Lo ve mi papá y mi mamá en la otra tele ve Lo que necesitas es amor".

La sintonía del "Telediario" es reconocida por todos los niños, y cada uno define y opina sobre lo que más le llama la atención de los informativos de manera peculiar, apreciamos como en algunas de sus visiones, sobre todo en las de los más mayores, algunos matices críticos: "Dicen cosas que han pasado y dan deportes, cultura no dan", "Salen muertos, si uno se ha caído o algo así", "salen cosas grandes",... Observamos como ya comienzan a aplicar algunas de nuestras explicaciones del apartado de contenidos conceptuales: "El señor que lo presenta no es un actor, es un presentador". 
Identifican la serie "Querido Maestro" los niños de seis y siete años, quienes también saben que día se emite y a qué cadena pertenece. Un niño de 7 años de clase media-alta afirma ser televidente asiduo: "Yo la veo todos los días por la noche", además describe su formato: "es una serie de televisión de la que echan muchos capítulos, como Médico de Familia...".

Seleccionamos un fragmento de la retransmisión del partido de fútbol entre el Extremadura y el F.C. Barcelona, emitido en directo el día anterior, con el fin de observar si el recurso sonoro palabra era identificado. Todos los niños lo identificaron, algunos -de sexo masculino- incluso dieron el nombre de los equipos y del resultado del encuentro, los más mayores afirmaron verlo hasta el final.

El programa cultural de La 2 de TVE "El Imperdible" no fue reconocido, mediante el audio, por ningún niño. Pese a ello describían lo que les sugería la música "son sevillanas...". Lo mismo ocurrió con el espacio "Hoy es posible" y con la serie "Los negocios de mamá". Desde el punto de vista de las actitudes, observamos que cuando los niños no identificaban la sintonía se mostraban pasivos y aburridos, comportamiento contrario al que se percibía cuando reconocían los programas.

Los niños más pequeños no reconocieron el programa "Quién sabe dónde", mientras que los de seis y siete años apresuradamente levantaban la mano como signo de que lo conocían, incluso sabían que se emite los lunes por la noche y la temática: "buscan personas que están huidas o algo así", pese a ello con sus aportaciones dedujimos que no lo ven: "es un programa para mayores".

Los documentales de La 2, a través de la sintonía de presentación, no fueron reconocidos por ningún niño, al igual que el programa divulgativo sobre gastronomía de Karlos Arguiñano, aspecto que sorprende puesto que por las láminas y cuestionarios sabemos que es uno de los preferidos y más vistos.

Como ya hemos ilustrado con las opiniones de los niños, establecen como criterio de distanciamiento entre lo que ven y lo que no, o entre lo que les gusta y lo que rechazan, que el programa sea "para mayores", lo que se vuelve a poner de manifiesto con "El programa de Ana", del que casi todos reconocen rápidamente la sintonía, la cadena y el horario de emisión pero justifican no verlo porque: "no es de niños, es de madres", también se percibe el criterio sexista que utilizan a la hora de perfilar quienes lo ven: "es de mujeres, mi padre no lo ve, es un rollo", afirma un niño de siete años de clase media-media.

De la serie juvenil "Hércules" podemos decir, que los niños de cuatro años no la reconocen por el nombre sino que la describen: "Hay una princesa y se pegan", sin embargo el resto de las edades la identifican y afirman verla. Otra serie, de las mismas características, "Vigilantes de la playa" no es reconocida por ninguno, a pesar de que en láminas y cuestionarios obtenemos datos de que sí la ven.

El concurso "La Ruleta de la Fortuna" es identificado por todos excepto por los niños de 4 años, los de 7 describen en qué consiste y la asocian con la cadena en la que se emite.

A modo de síntesis, podemos concluir que, tal y como afirmaba Bruner, los niños más pequeños, salvo en algunos casos, no logran asociar la imagen visual con la auditiva, lo que se evidencia en los niños de cuatro años, en los que pese a que tenemos constancia por las láminas de que ven algunos programas de los que hemos seleccionado las sintonías, no las reconocen, lo que no ocurre con la imagen icónica que representan las láminas. Mientras que en el resto de las edades se observa la relación que establecen entre el elemento audio y el visual, por lo que estos niños se mostraron más motivados en la escucha y participación en esta 
discusión dirigida. También se aprecia que las sintonías que además de música tienen letra son más recocidas, lo que justifica que algunos programas como el de Karlos Arguiñano no sean identificados a pesar de ser los más vistos por esta muestra de la audiencia.

\subsection{Sesiones con imagen en movimiento}

La grabación de cada una de las sesiones de trabajo nos sirvió como recurso para el estudio de las actitudes y comportamientos que mostraban los niños. Comprobamos que no se sentían extraños por la presencia de la cámara sino, al contrario, les gustaba ponerse delante siendo ellos los protagonistas.

Como en anteriores ejercicios, proseguíamos con la explicación y enseñanza de los contenidos conceptuales: diferencias entre los distintos medios de comunicación y su utilidad, los fundamentos técnicos de la televisión, distinción entre realidadficción, entre géneros y formatos, y entre persona y personaje, etc.

En las sesiones destinadas al visionado de la imagen en movimiento, se eligieron los siguientes espacios televisivos:

- Programación infantil: "Inspector Gadget”, "El Príncipe Valiente”, "Los Pitufos”

y "Barrio Sésamo".

- Teleseries juveniles: "Los Vigilantes de la Playa" y "Hércules".

- Teleseries para adultos: "Querido Maestro", "Médico de Familia" y "Hostal Royal Manzanares".

- Realty show: "Sorpresa, sorpresa", "Impacto Tv" y "Esta noche cruzamos el Mississippi".

- Película: "A la caza del octubre rojo".

- Anuncios publicitarios.

A continuación, transcribimos algunos momentos de las sesiones didácticas que se realizaron a modo de grupos de discusión:

P.- Qué es para ti la TV?

R.- Una pantalla que tiene, que hacen cosas y no se pueden hacer y hacen como si fuera verdad (7 años).

R.- Es una cosa que si la mojas encendida te da electricidad. (6 años).

R.- y es para ver los canales.

R.- veo los dibujos, las series y películas.

R.- Es una cosa para ver dibujos animados, películas y cosas así (6 años).

P.- ¿Para qué sirve?

R.- Es para ver cosas, aprender de animales, para aprender gimnasia, inglés. (7 años).

R.- Sirve para ver las noticias. Es una pantalla donde se ven los dibujos animados.

R.- Es la misma que se ve en otras casas ( 7 años).

P.-¿En qué se diferencian?

R.- por los señores que trabajan en los cables y hacen los trabajos.

P.- ¿Quiénes ponen lo que sale en la tele?

R.- Pues los señores, la electricidad. 
** En este punto EXPLICAMOS lo que son los técnicos y los programadores de televisión.

P.- ¿Qué es un periódico?

R.- es un papel en el que vienen informaciones (6 años).

R.- está escrito y dibujado (5 años).

R.- da las noticias en dibujos y en letras (6 años).

P.- ¿Qué es el cine?

R.- es una sala grande donde ponen las películas.

P.- ¿Qué es la radio?

R.- una cosa para oír el telediario y música.

P.- ¿En qué se diferencia la radio de la televisión?

R.- En que en la radio no se ve y en la televisión se ve.

** EXPLICACIÓN de lo que es una cámara de vídeo y sus diferencias con el resto de los medios. Imagen fija e imagen en movimiento.

R.- La cámara de vídeo graba las imágenes en movimiento y la cámara de fotos las graba quietas. (7 años).

R.- La cámara de fotos hace fotos y la de vídeo graba. (7 años).

R.- La cámara de vídeo tiene un pico para ver, y la otra no. (4 años).

R.- Una necesita un cable y la otra no. (5 años).

${ }^{* *}$ EXPLICACIÓN de micrófonos y altavoces.

P.- ¿Qué entra por el micrófono?

R.- la voz y el sonido. (6 años).

${ }^{* *}$ EXPLICACIÓN formatos y géneros televisivos.

** VISIONADO vídeos programación infantil.

\section{EL PRÍNCIPE VALIENTE}

Bajo índice de reconocimiento, hay 8 niños en esta sesión y lo reconocen 2 con su nombre (6 y 7 años), los demás dicen que lo ven a veces. Les gusta por ser divertido, guapo, valiente, etc. Observamos que los criterios de selección coinciden con los expuestos en el estudio de imagen fija (láminas).

\section{INSPECTOR GADGET}

Todos lo reconocen, les gusta, explican que es bueno porque es policía. Conocen los nombres de los personajes que salen, y dicen verlo habitualmente.

\section{PITUFOS}

Reconocimiento al 100\%. Identificación chicos con Pitufos, y chicas con Pitufina.

P.- ¿Existen los Pitufos?

R.-No existen, son de mentira, son como marionetas (6 años). 
Alto reconocimiento, pese a que los niños de 4 años no lo identifican. Lo ven habitualmente y les gusta.

R.- Sirve para aprender cosas.

R.- Sirve para divertirse.

R.- Para informarse de cosas.

P.- ¿Las películas de mayores os gustan?

R.-!!SI!!!, pero no las que dan miedo.

P.- ¿Qué diferencia hay con éstas?

R.- Esas las hacen con muñecos y lo hacen los niños y lo de mayores, lo hacen los mayores.

** Visionado de series juveniles

LOS VIGILANTES DE LA PLAYA

Alto reconocimiento, excepto los niños de 4 años, que apenas intervienen en la sesión.

R.- Son personas que salvan a la gente.

R.- lo echan de lunes a viernes en Antena 3 (los de 7 años).

P.- ¿Cómo llamamos a este tipo de películas?

R.- una serie de televisión.

** Visionado de programación para adultos

QUERIDO MAESTRO

Alto reconocimiento, lo ven habitualmente.

R.- Es una serie.

P.- ¿Mario es una persona de verdad o qué es?

P.- Es un personaje.

MÉDICO DE FAMILIA

Alta identificación, lo ven habitualmente. Conocen los nombres de los personajes.

Diferencian muy bien a Emilio Aragón del personaje de Nacho.

SORPRESA-SORPRESA

Alto reconocimiento, también de su presentadora, Isabel Gemio. Lo ven pero no hasta que acaba.

P.- ¿Por qué te gusta?

R.- Porque da muchas sorpresas y mucha alegría.

R.- A mí me gusta cuando lloran.

R.- Pues a mi tampoco me gusta cuando lloran, me da pena..

(Se ponen a cantar la sintonía del programa, se la saben todos: Acompáñame una noche más...).

PELÍCULA "A LA CAZA DEL OCTUBRE ROJO"

P.- ¿Quién la vio?

R.- Yo la vi un rato. (5 años). 
R.- Yo también. ( 7 años).

R.- Mi padre. (4 años).

P.- ¿De qué era la película?

R.- Es una peli de miedo.

(Los demás no la vieron ninguno, y dicen que las películas de miedo no les gustan).

P.- ¿Por qué?

R.- Porque matan.

R.- porque me da asco...

R.-Pero es tomate la sangre, no hay sangre de verdad. (le contesta otro niño)

\section{ESTA NOCHE CRUZAMOS EL MISSISSIPPI}

Lo reconocen niños de todas las edades. De los 8 que hay en esta sesión dicen verlo 3. Conocen el nombre de Pepe Navarro.

R.- Es un programa de personas y da risa (5 años).

R.- Lo ve mi padre. (5 años)

R.- Sale una mujer en top-less. (7 años).

R.- Sale una estatua. (4 años).

P.- ¿Cómo se llama ese señor?

R.- !!Pepe Navarro!! (lo reconocen todos).

IMPACTO TV

Lo reconocen todos y dicen verlo frecuentemente. Les gustan "los choques y las caídas".

P.- ¿Esto, es realidad o ficción?

R.- Es ficción. (4 años).

P.- ¿Por qué?

R.- Porque lo echan en la tele (6 años).

R.- Porque son películas que matan (5 años).

PUBLICIDAD

Anuncio "Heineken"- ("Caperucita").

R.- Es de una cerveza, de Buckler.

R.- Es Heineken o Laiker.

R.-Caperucita es de niños, pero la cerveza no.

Anuncio autopromoción entrevista a J. Mํㅡㄹ AZNAR en Tele 5.

P.-¿De qué se trata?

R- De un informativo.

P.- ¿Quién es éste?

R.- Felipe González.

R.- El del PP

R.- El Aznar.

R.- Es del partido socialista.

R.- Es el Presidente del Gobierno. 
P.- ¿Y este señor en qué trabaja?

R.- En ordenar España.

R.- Es un Presidente.

Otro spot de zapatillas en el que interviene Ronaldo, todos lo reconocen y dicen que lo han visto. Todos gritan entusiasmados el nombre del jugador de fútbol, tanto niños como niñas, lo que ocasiona un gran alboroto al verlo.

P.- ¿En qué equipo juega?

R.- En el Barcelona. (Responde la mayoría).

Pasamos imágenes de algunos anuncios, sin sonido.

P.-¿Quién los ve?

P.- ¿A quién le gustan?

R.- A mí, por qué sale comida y juguetes. (4 años).

Reconocimiento de todos los anuncios, conocen los productos de los que se trata y las marcas a las cuales pertenecen. Nos cantan las canciones de "Águila Amstel" y la correspondiente al "Gigante Verde".

P.- ¿Vamos a ver, la publicidad, para qué sirve?

R.- Para dar un descanso a la película. (6 años).

R.- Para descansar (5 años).

P.- ¿Qué nos ponen en la publicidad?

R.-ponen anuncios de películas.

R.- ponen anuncios de la Spice-girls.

R.- ponen anuncios de Coca-cola.

R.-te dicen lo que van a echar.

R.- te dicen las pelis que va a haber.

P.- ¿Y para qué lo ponen?

R.- para que compremos y para que aprendamos.

P.- ¿Para que aprendamos qué?

R.- como se llaman las cosas.

La publicidad les gusta a todos, pero dicen no prestar mucha atención, salvo a los anuncios que les gustan, sobre todo los de juguetes.

** Como en anteriores ejercicios, volvemos a EXPLICAR las diferencias entre persona y personaje y actor, ejemplificado con el personaje de "Reme" de la serie "Hostal Royal Manzanares" interpretado por Lina Morgan, conocida por todos los niños del grupo.

P.- ¿Qué hacen los actores?

R.- Hacen películas (7 años).

R.- Puede ser una cosa en una película, pero de verdad no lo es. (7 años).

P.- ¿Entonces, qué es? 


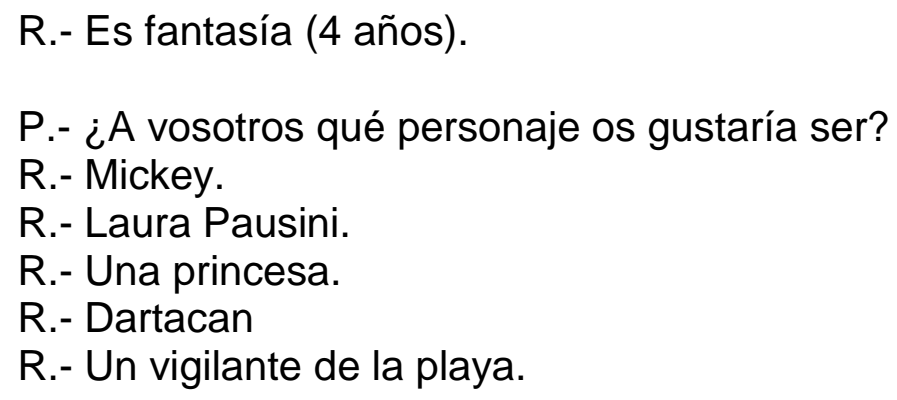

Hay que señalar que, a través de la imagen en movimiento, se hace más patente la identificación por sexos, los chicos siempre con personajes masculinos y las chicas siempre con femeninos.

P.-¿Por qué te gustaría ser un vigilante de la Playa?

R.- Porque me gusta nadar.

R.- Porque me gusta estar en la playa.

R.- Porque así salvaría a gente.

(...)

P.- ¿Pero, nosotros qué somos, de verdad?

R.- Personas.

P.- ¿Y el señor que sale en el telediario, es un personaje o es el mismo señor de verdad?

R.- Es un señor de verdad. (Todos).

P.- ¿Y qué oficio tiene, como se llama?

R.- Es un periodista.

R.- Es un presentador .

** EXPLICACIÓN de las diferencias entre realidad y ficción.

P.- ¿En las noticias cuando sale un accidente, es de mentira?

R.- No, es de verdad (6 años).

R.- Los telediarios son de miedo, porque lo que dicen es de verdad (7 años).

R.- Me dan miedo las películas de miedo (5 años).

R.- A mi las que matan (4 años).

R.- A mi no me gusta que muera la gente (4 años).

P.- ¿Por qué?

R.- Porque crees que te puede pasar a ti.

P.- ¿A ti te puede perseguir un monstruo?

R.- No porque no existen, son de mentira.

P.- Entonces, si son de mentira, ¿por qué nos da miedo?

R.- Porque parecen de verdad (4 años).

R.- pero utilizan trucos (5 años).

P.- ¿Trucos como cuáles? 
R.-Efectos especiales (7 años).

P.-¿Para qué sirven los efectos especiales?

R.- en las películas ponen tomate para que crea que es sangre, me lo ha explicado mi padre (5 años).

R.- ...y si te tiras de un rascacielos no te matas (4 años).

R.-Meten chinchetas en las pistolas y cuando pinchan las bolsas con tomate, sale y parece sangre. (6 años).

P.- ¿Quién te ha contado eso?

R.- Mi madre (6 años).

P.- ¿Quién elige en casa los canales de TV?

R.-Entre toda la familia.

P.-¿Y lo que echan por la tele?

R.- Lo eligen los que lo hacen.

P.- ¿Os gustaría elegir lo que echan en cada cadena por la tele?

R.- (No contestan).

** Finalizamos la sesión tratando de hacer una recopilación de los contenidos tratados, preguntando a los niños qué habían aprendido.

P.- ¿Qué hemos aprendido?

R.- Que unas cosas son de verdad y otras mentira.

R.- Qué es un personaje, que la sangre en las películas es tomate. (7 años).

R.- Que nos engañan en la tele, porque Caperucita que era de un cuento, es un anuncio

(7 años).

R.- Los dibujos son de mentira. (5 años).

R.- El Inspector Gadget es un muñeco que hace que es una persona. (6 años).

P.- ¿Y cómo llamamos a eso?

R.-!!Personaje!!. (lo sabían todos).

R.- En dibujos lo matan un día y luego otro día vuelve a salir. (6 años).

R.- Porque son de dibujos y son de mentira.

R.- Pero tu ves una cosa de terror y sueñas con ella. (5 años).

R.- En las películas de los mayores sale la violencia. (7 años)

P.- ¿Qué es la violencia?

R.- Matar a gente, secuestrar, meter a gente en la cárcel,.. (6 años).

R.-A veces son amigos y uno va y lo tira al otro por la ventana, y no lo entiendo. (7 años).

P.- ¿Entonces, en las películas, pasan las cosas de verdad?

R.- !!NO!!

P.- ¿Las películas que son?

R.- Señores que hacen cosas. 
R.- La ficción.

P.- ¿Y la ficción qué es?

R.- lo de mentira.

R.- Lo que sale en los informativos sí es de verdad. (7 años).

R.- En el telediario salen cosas de verdad, son cosas que le pasan a la gente (6 años).

P.- ¿Qué son las noticias?

R.-Son las cosas que le pasan a la gente (6 años).

P.- ¿Quién las presenta?

R.- Un señor que dice cosas porque se ha enterado, un presentador. (7 años)

P.- ¿Qué diferencia existe entre los informativos y las películas?

R.- En lo informativos cuando matan es de verdad. (7 años).

R.- Mario Bross cuando está en la telaraña salta y coge carrerilla y saltaba. (4 años).

P.- ¿Eso es posible?

R- No.

P.- ¿Tú lo podrías hacer?

R.- No.

P.- ¿Qué pasaría si lo hiciéramos?

R.- Que nos podríamos hacer mucho daño.

R.- En las películas son cosas que se inventa la gente.

P.- ¿Quién se inventa las películas?

R.- No tengo ni idea (5 años).

R.- Los que tienen las pistolas para matar. (4 años).

P.- ¿Qué os gusta más de lo que sale en la tele?

R.- las películas de niños (4 años).

R.- los dibujos animados (4 años).

A casi todos les gusta lo mismo.

P.- ¿Qué es aburrido en la tele?

R.- las noticias.

R.- el telediario.

\section{Conclusiones}

Los sujetos de la investigación del grupo experimental, niños de 4 a 7 años, despiertan una visión crítica y, por tanto, no son seres pasivos que se alimentan indiscriminadamente de lo que les ofrecen los medios audiovisuales sino personas que comienzan, en su temprana edad, a seleccionar lo que quieren ver y oír y saben discernir entre la realidad de su entorno y la que aparece reflejada en la televisión; constituyendo este medio una forma de entretenimiento, aprendizaje o información, 
pero conociendo y sabiendo el uso que en cada momento quieren hacer, aspecto relevante si tenemos en cuenta la sobrecarga de programación y el número de horas que los más pequeños pasan ante la pequeña pantalla.

$\mathrm{Si}$ bien son escasos los programas concebidos como televisión educativa específicamente, el impacto de la televisión cambia de manera sustancial la forma de educar. Los educadores deben de ser conscientes de la existencia y del impacto de los medios y nuevas tecnologías en la sociedad actual, y por su parte los programadores no deben olvidarse de las premisas y las exigencias de la educación. Los niños se aferran a las imágenes en sí mismas más que a lo que esas imágenes contienen o transmiten. En este estudio, hemos podido constatar cómo el índice de reconocimiento es mayor en el caso de imágenes en movimiento que en la imagen fija. El menor índice de identificación corresponde a las sintonías y sonidos de diferentes programas televisivos.

Entre sus preferencias no se sitúa en primer lugar ver la televisión, sino jugar con sus amigos o hermanos. Sin embargo, en la oferta de medios de comunicación, el que más les gusta y más utilizan es la imagen de la televisión o el vídeo.

No hemos apreciado diferencias significativas en cuanto a percepción, conocimientos y actitudes frente al medio televisivo, teniendo en cuenta los tres estratos de la clase social elegidos para el estudio (media-baja, media-media y media-alta).

A partir de los cuatro años los niños comienzan a establecer el criterio sexista en sus elecciones y es, a través de la imagen en movimiento donde se hace más patente esta identificación por sexos: los niños con personajes masculinos y las niñas con femeninos.

Desde los cinco años de edad se observa que después de las sesiones de aprendizaje los sujetos experimentales muestran una notable variación en cuanto a sus conocimientos y actitudes críticas, respecto a los sujetos de control, en cuanto a los contenidos televisivos establecidos.

\section{Bibliografía básica}

AA.VV. (Dirección Ricardo Berea): Análisis de la demanda de servicios para la primera infancia. Ed. Ministerio de Asuntos Sociales. Madrid, 1992.

AA.VV. (Dirección Sergio Sánchez Cerezo): Enciclopedia de la Educación Infantil. Recursos para el desarrollo del currículum. Ed. Santillana Infantil. Madrid, 1993.

AA.VV. (Dirección Ejecutiva: Agustín García Matilla): La televisión educativa en España. Informe Marco. Ministerio de Educación y Ciencia. Madrid, 1996.

APARICI, R.: Educación para los medios en tiempos del neoliberalismo. Actas del I Congreso Internacional de Formación y medios. Segovia, 1997.

APARICI, R. y GARCÍA MATILLA, A.: Imagen, vídeo y educación. Ed. Fondo de Cultura Económica, Paideia. Madrid, 1987.

CLOUTIER, J.: L'ère d'EMEREC ou la communication audio-scripto-visuelle à I'heure des self-média. Les Presses de L'Université de Montreal, Montreal, 1975. 
CHERRY, C.: El arte del niño en edad preescolar. CEAC. Barcelona, 1988.

EINES, J. y MANTOVANI, A.: Teoría del juego dramático. Ed. Instituto Nacional de Comunicación de la Educación. Madrid, 1980.

GALLEGO, J.: El consumo televisivo: discursos y estrategias. Ed. Centro de Investigaciones Sociológicas. Siglo Veintiuno de España Editores. Madrid, 1995.

HIMMELWEIT, H.; OPPENHEIM, A. y VINCE, P.: Television and the child: An empiral study of the effects of television on the young. Oxford University Press. Londres, 1958.

KAPLÚN, M.: Continuidades y rupturas en las búsquedas de un comunicadoreducador. Ponencia en el IV Congreso Internacional de Pedagogía de la Imagen. Coruña, 1995.

LANDIVAR, T. E.: Hacia una comunicación educativa alternativa, en Medios Audiovisuales, núm. 171. Madrid.

MANTOVANI, A.: El teatro: un juego más. Ed. Nuestra Cultura, Serie Pedagogía-De cero a seis. Madrid 1980.

MASTERMAN, L. : La enseñanza de los medios de comunicación. Ed. de la Torre. Madrid, 1985.

MASTERMAN, L: Una educación para el mundo actual, ponencia en el Congreso "10 años de Lectura de la Imagen". Madrid, 1997.

MORAGAS, M.: Comunicación Alternativa y Tipología de los Medios. Revista del Ministerio de Educación y Ciencia. Madrid, 1982.

MORENO, I.: Nuevas tecnologías y creación audiovisual. De la pasividad receptora a la interactividad constructiva. Ponencia en el " $\mathrm{V}$ Congreso Infancine 96". Madrid, 1996.

PIAGET, J.: El nacimiento de la inteligencia en el niño. Aguilar. Madrid, 1969.

POSTMAN, N.: Amusing Ourselves to Death. Public Discouse in the Age of Show Bussiness. Methuen, 1985. Publicado en castellano por Ed. La Tempestad. Barcelona, 1991.

RIOBOO, J.: Qué hacemos con los niños, artículo publicado en PEÑAFIEL, C.; IBAÑ̃E, J.L. y CASTILLA, M.: La televisión que viene. Servicio Editorial Universidad del País Vasco. Bilbao, 1990.

RICO, L.: TV: Fábrica de mentiras. Espasa-Calpe. Madrid, 1992. 
RICO, L.: La vida no es un invento mío, en MARCH, J. C.: La generación televisión. Ed. Escuela Andaluza de Salud Pública. Granada, 1994.

SCHRAMM, W.; LYLE, J. y PARKER, E. Television in the lives of our children. Stanford Universitity Press. Stanford, California, 1961.

VILCHES, L: La televisión. Los efectos del bien y del mal. Paidós Comunicación. Barcelona, 1993. 